\title{
Optimal Power Flow-Based Calculation of Transmission Constraint Cost
}

\author{
Soonhyun Hwang and Balho H. Kim \\ Power Economics, Electronic and Electrical Engineering, Hongik University, South Korea
}

\begin{abstract}
As the construction of High Capacity transmission lines becomes a social issue, construction conditions of power system are being worsened, resulting in the decrease of power supply capacity and increase of supply costs. Because of this, feasibility for construction of High Capacity transmission lines needs to be explained logically, and the most effective method is to present economic effects such as the change of transmission constraint costs and power production costs. This paper intends to propose an Optimal Power Flow(OPF)-based method for calculation of constraint costs due to the construction of new transmission lines and to use it in order to perform case study for High Capacity transmission lines which will be constructed in Republic of Korea.
\end{abstract}

\section{Introduction}

Currently, Korean electric power industry faces the introduction and operation of competitive generation and greater importance of private generation companies, but as the construction of High Capacity transmission lines becomes a social issue, power system construction conditions are being worsened, making restrictions on power generation businesses of the transmission company as well as generation companies. It results in the decrease of power supply capacity, and unstable demand supply and increased supply costs in the long term. Because of this, feasibility for construction of High Capacity transmission lines needs to be explained logically to the public, and the most effective method is to present economic effects such as the change of transmission constraint costs and power production costs.[1]

Optimal Power Flow(OPF) is an advanced technique for performing Economic Dispatch and Power Flow calculations at the same time in order to determine output levels of each generators in the most economical way. It is effective for analyzing the economic effect of a system plan, as it can determine optimal(economical) output by considering transmission constraints and handle constraint cost calculation logically.[2]

This paper intends to propose an OPF-based method for calculation of constraint costs due to the construction of new transmission lines and to use it in order to perform case study for High Capacity transmission lines which will be constructed in Republic of Korea.

\section{Method of calculating OPF-based constraint cost}

Power supply costs with and without new transmission lines were compared to calculate constraint costs due to the construction of new transmission lines. Determining the Generator Maintenance Scheduling and the operation status(On/Off) of each unit and time may be an optimal method to calculate power supply costs for each case, but this paper ignores the Generator Maintenance Scheduling by considering practical limitations and replaces Unit Commitment with a plan to determine the operation status of units.

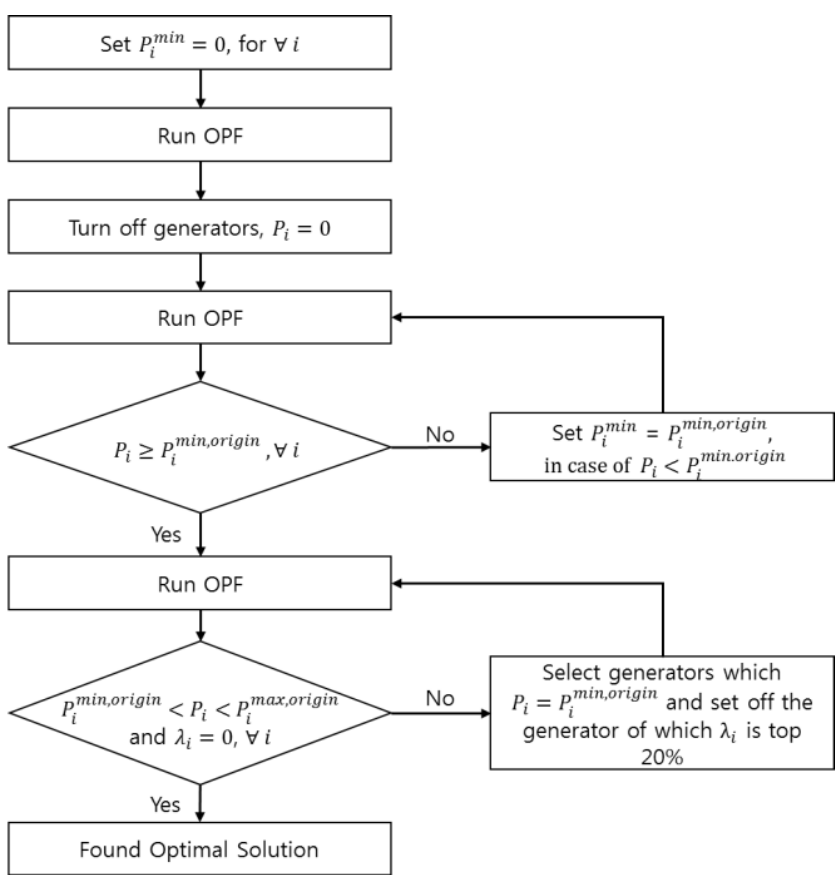

Figure 1. An algorithm for calculating the constraint cost of new transmission lines using OPF.

Figure 1 shows an algorithm for calculating the constraint cost of new transmission lines which uses OPF established in this study. 
Where,

i : Generator number

$\mathrm{P}_{\mathrm{i}}$ : Power produced by generator $\mathrm{i}$

$\mathrm{P}_{\mathrm{i}}^{\text {min }}$ : Minimum generation constraint of generator $\mathrm{i}$

$\mathrm{P}_{\mathrm{i}}^{\text {min,origin }}$ : Original minimum generation constraint of generator i

$\mathrm{P}_{\mathrm{i}}^{\text {max,origin }}$ : Original maximum generation constraint of generator i

$\lambda_{\mathrm{i}}:$ Lagrange multiplier of generator $\mathrm{i}$

The details of the algorithm process are as follows.

1) Minimum generation constraints of all units are set to zero and OPF is performed

- It is to determine the run(on) or stop(off) of units first and units of which generation is zero after OPF are targeted.

2) Units of which output is zero is stopped(off) on the basis of the result in step 1)

3) Units of which generation is below it's original minimum generation constraint are identified

- Units of which generation is below it's original minimum generation constraint(before set to zero) are selected among units which are running(On) in step 2). If all units generate power above it's original generation constraint of each, progress is made to step 5).

4) Minimum generation constraints are restored

- For units selected in step 3), minimum generation constraints are restored to the previous values(before set to zero). OPF is performed again and return is made to step 3) to check if there are units of which generation is below minimum generation.

5) Units restricted by minimum generation constraint are identified

- If all units are not restricted by minimum generation constraint, the current status is the optimal solution which can satisfy demand with the lowest cost. If there are units restricted by minimum generation constraint, however, these units can be stopped(off) to further reduce total generation costs. Lagrange multiplier $(\lambda)$ is used as a criterion for determining which unit is to be stopped(off).[3]

6) Units to be stopped (off) are selected

- Units restricted by minimum generation constraint in step 5) are sorted in the order of $\lambda$, and among them, units of which the absolute value of $\lambda$ belongs to top $20 \%$ are stopped. Then, return is made to step 5) and the step is performed repetitively. It is ideal that only one unit with the biggest $\lambda$ is stopped and return is made to step 5), but this method takes very long time. On the contrary, if too many units are stopped to reduce processing time, total costs are made above the optimal solution. This paper proposes top $20 \%$ as a baseline, because repetitions proved empirically that it is most appropriate.

\section{Case study}

In this section, the procedure introduced in the above section is used to calculate transmission constraint costs for High Capacity transmission lines which will be constructed in Republic of Korea. In this study, transmission constraint cost is calculated as the difference in total generation costs between non-constrained supply and constrained supply which considers thermal capacity or stability constraints. This study uses PSS/E OPF as the OPF tool which solves a nonlinear problem consisting of an objective function and a linear combination of equality constraints to form a scalar Lagrangian function. [4] Other basic premises are as follows.

\subsection{Basic premises}

- Analysis is performed for the actual system in Republic of Korea and the High Capacity transmission lines are two lines with 7,290 MW capacity and $222 \mathrm{~km}$ length which will be completed in December 2019.

- Analysis period is total three years (2020 to 2022) and completion delay is set in the unit of six months to make total six scenarios.

- Load levels are $100 \%, 90 \%, 80 \%, 70 \%$ and $60 \%$ (total five levels), and averages of the recent three years are used for the number of days in a year for each load level. - New and abolished facilities are based on the 6th Basic Plan for Long-Term Electricity Supply and Demand.[5]

New units which will be operated in the future are set discretionally as there is no correct information on the cost function. It is likely that new units will have highest priority of receiving Dispatching Instruction among those of the same type, as they clearly have better generation efficiency and lower generation costs than the currently operated units. Because of this, the above criterion has been applied to set the cost function of new units and the method is as follows.

- Facilities with the lowest generation cost are selected among generation source-specific units.

- The cost function coefficient of the selected units is decreased as much as $2 \%$ and then applied.

When selecting units with the lowest generation cost, cost functions of units are drawn in graphs and the graph in the lowest position is selected as a standard unit. As the graph of the selected cost function, however, does not always have the lowest value in all sections when compared with other facilities, the function coefficient is adjusted to generate the lowest value in all sections. At the time, $2 \%$ of decrease has been determined empirically to be optimum. If the decrease is smaller than $2 \%$, Dispatching Instruction instructions have not been received preferentially sometimes, and if it is larger than $2 \%$, total generation costs have been lowered too much. $2 \%$ set in this study, however, is not absolute and the cost function of a new generation unit has to be input more correctly in order to increase the reliability of the result value.

Table 1 shows the cost function of each generator type. Nuc, Ther, Com and CHP indicates Nuclear, Thermal, Combined power and Combined Heat and power.

Table 2 shows detailed scenarios for each load level and period. Timely completion $(\mathrm{T} / \mathrm{C})$ indicates the existence of new transmission lines in the corresponding 
period and delayed completion(D/C) indicates the nonoperation of certain units in the corresponding period due to the delayed completion of new lines. Each scenario represents total generation cost for one hour in the corresponding load level.

Table 1. Cost function of new generator units.

\begin{tabular}{|c|c|c|}
\hline \multicolumn{2}{|c|}{ Type } & Cost Function \\
\hline \multirow{2}{*}{ Nuc } & Standard & $0.000105 P^{2}+2.043505 P+267.815413$ \\
\cline { 2 - 3 } & New & $0.000103 P^{2}+2.002635 P+262.459105$ \\
\hline \multirow{2}{*}{ Ther } & Standard & $0.000098 P^{2}+1.856711 P+169.666484$ \\
\cline { 2 - 3 } & New & $0.000096 P^{2}+1.819577 P+166.273154$ \\
\hline \multirow{2}{*}{ Com } & Standard & $0.000021 P^{2}+1.620993 P+23.917894$ \\
\cline { 2 - 3 } & New & $0.0000206 P^{2}+1.58857 P+23.4395361$ \\
\hline \multirow{2}{*}{ CHP } & Standard & $0.000382 P^{2}+1.498898 P+62.204427$ \\
\cline { 2 - 3 } & New & $0.000374 P^{2}+1.46892 P+60.9603385$ \\
\hline
\end{tabular}

Table 2. Detailed scenarios for each load level and period.

\begin{tabular}{|c|c|c|c|c|c|c|c|c|c|c|c|c|}
\hline Year & \multicolumn{4}{|c|}{2020 , } & \multicolumn{4}{|c|}{ 2021' } & \multicolumn{4}{|c|}{ 2022' } \\
\hline Load & $\begin{array}{l}\text { First } \\
\text { half }\end{array}$ & t & $\begin{array}{l}\text { Seco } \\
\text { half }\end{array}$ & $\begin{array}{l}\text { nd } \\
\text { year }\end{array}$ & $\begin{array}{l}\text { Firs } \\
\text { half }\end{array}$ & t & $\begin{array}{l}\text { Seco } \\
\text { half }\end{array}$ & $\begin{array}{l}\text { ond } \\
\text { year }\end{array}$ & $\begin{array}{l}\text { Firs } \\
\text { half }\end{array}$ & t & $\begin{array}{l}\text { Seco } \\
\text { half }\end{array}$ & \\
\hline $90 \%$ & $\mathrm{~T} / \mathrm{C}$ & $\mathrm{D} / \mathrm{C}$ & $\mathrm{T} / \mathrm{C}$ & $\mathrm{D} / \mathrm{C}$ & $\mathrm{T} / \mathrm{C}$ & $\mathrm{D} / \mathrm{C}$ & $\mathrm{T} / \mathrm{C}$ & $\mathrm{D} / \mathrm{C}$ & $\mathrm{T} / \mathrm{C}$ & $\mathrm{D} / \mathrm{C}$ & $\mathrm{T} / \mathrm{C}$ & $\mathrm{D} / \mathrm{C}$ \\
\hline $80 \%$ & $\mathrm{~T} / \mathrm{C}$ & $\mathrm{D} / \mathrm{C}$ & $\mathrm{T} / \mathrm{C}$ & $\mathrm{D} / \mathrm{C}$ & $\mathrm{T} / \mathrm{C}$ & $\mathrm{D} / \mathrm{C}$ & $\mathrm{T} / \mathrm{C}$ & $\mathrm{D} / \mathrm{C}$ & $\mathrm{T} / \mathrm{C}$ & $\mathrm{D} / \mathrm{C}$ & $\mathrm{T} / \mathrm{C}$ & $\mathrm{D} / \mathrm{C}$ \\
\hline $70 \%$ & $\mathrm{~T} / \mathrm{C}$ & $\mathrm{D} / \mathrm{C}$ & $\mathrm{T} / \mathrm{C}$ & $\mathrm{D} / \mathrm{C}$ & $\mathrm{T} / \mathrm{C}$ & $\mathrm{D} / \mathrm{C}$ & $\mathrm{C}$ & $\mathrm{D} / \mathrm{C}$ & $\mathrm{T} / \mathrm{C}$ & $\mathrm{D} / \mathrm{C}$ & $\mathrm{T} / \mathrm{C}$ & $\mathrm{D} / \mathrm{C}$ \\
\hline $60 \%$ & $\mathrm{~T} / \mathrm{C}$ & $\mathrm{D} / \mathrm{C}$ & $1 / 0$ & $/ \mathrm{C}$ & $\mathrm{T} / \mathrm{C}$ & $\mathrm{D} / \mathrm{C}$ & $\mathrm{T} / \mathrm{C}$ & $\mathrm{D} / \mathrm{C}$ & $\mathrm{T} / \mathrm{C}$ & $\mathrm{D} / \mathrm{C}$ & $\mathrm{T} / \mathrm{C}$ & $c$ \\
\hline $50 \%$ & $\mathrm{~T} / \mathrm{C}$ & $\mathrm{D} / \mathrm{C}$ & $\mathrm{T} / \mathrm{C}$ & $\mathrm{D} / \mathrm{C}$ & $\mathrm{T} / \mathrm{C}$ & $\mathrm{D} / \mathrm{C}$ & $\mathrm{T} / \mathrm{C}$ & $\mathrm{D} / \mathrm{C}$ & $\mathrm{T} / \mathrm{C}$ & $\mathrm{D} / \mathrm{C}$ & $\mathrm{T} / \mathrm{C}$ & $\mathrm{D} / \mathrm{C}$ \\
\hline
\end{tabular}

\subsection{Results of case study}

Table 3. Hourly generation costs for each scenario. (Unit: thousand KRW)

\begin{tabular}{|c|c|c|c|}
\hline \multicolumn{2}{|c|}{ Year } & \multicolumn{2}{|c|}{2020} \\
\hline Load & Case & First half year & Second half year \\
\hline \multirow{2}{*}{$100 \%$} & $\mathbf{T} / \mathbf{C}$ & $3,602,298$ & $3,801,023$ \\
\hline & $\mathrm{D} / \mathrm{C}$ & $3,971,447$ & $4,252,038$ \\
\hline \multirow{2}{*}{$90 \%$} & $T / C$ & $2,647,932$ & $2,813,253$ \\
\hline & $\mathrm{D} / \mathrm{C}$ & $3,017,746$ & $3,275,540$ \\
\hline \multirow{2}{*}{$80 \%$} & $T / C$ & $1,782,651$ & $1,847,402$ \\
\hline & $\mathrm{D} / \mathrm{C}$ & $1,904,375$ & $2,126,644$ \\
\hline \multirow{2}{*}{$70 \%$} & $\mathrm{~T} / \mathrm{C}$ & $1,454,792$ & $1,513,545$ \\
\hline & $\mathrm{D} / \mathrm{C}$ & $1,476,688$ & $1,532,881$ \\
\hline \multirow{2}{*}{$60 \%$} & $\mathrm{~T} / \mathrm{C}$ & $1,137,197$ & $1,185,121$ \\
\hline & $\mathrm{D} / \mathrm{C}$ & $1,151,797$ & $1,205,175$ \\
\hline \multicolumn{2}{|c|}{ Year } & \multicolumn{2}{|c|}{2021} \\
\hline Load & Case & First half year & Second half year \\
\hline \multirow{2}{*}{$100 \%$} & $T / C$ & $3,624,048$ & $3,731,809$ \\
\hline & $\mathrm{D} / \mathrm{C}$ & $4,067,804$ & $4,401,112$ \\
\hline \multirow{2}{*}{$90 \%$} & $\mathrm{~T} / \mathrm{C}$ & $2,658,845$ & $2,736,267$ \\
\hline & $\mathrm{D} / \mathrm{C}$ & $3,104,049$ & $3,400,434$ \\
\hline $80 \%$ & T/C & $1,797,932$ & $1,813,831$ \\
\hline
\end{tabular}

\begin{tabular}{|c|c|c|c|}
\hline & D/C & $1,952,717$ & $2,234,828$ \\
\hline \multirow{2}{*}{$\mathbf{7 0} \%$} & T/C & $1,464,208$ & $1,476,342$ \\
\cline { 2 - 4 } & $\mathbf{D} / \mathbf{C}$ & $1,485,835$ & $1,502,350$ \\
\hline \multirow{2}{*}{$\mathbf{6 0} \%$} & $\mathbf{T} / \mathbf{C}$ & $1,141,364$ & $1,149,327$ \\
\cline { 2 - 4 } & $\mathbf{D} / \mathbf{C}$ & $1,155,435$ & $1,159,132$ \\
\hline \multicolumn{2}{|c|}{ Year } & \multicolumn{2}{|c|}{$\mathbf{2 0 2 2}$} \\
\hline \multirow{2}{*}{$\mathbf{1 0 0} \%$} & $\mathbf{T} / \mathbf{C}$ & $3,731,809$ & $3,560,931$ \\
\cline { 2 - 4 } & $\mathbf{D} / \mathbf{C}$ & $4,401,112$ & $4,371,199$ \\
\hline \multirow{2}{*}{$\mathbf{9 0} \%$} & $\mathbf{T} / \mathbf{C}$ & $2,736,267$ & $2,559,920$ \\
\cline { 2 - 4 } & $\mathbf{D} / \mathbf{C}$ & $3,400,434$ & $3,375,452$ \\
\hline \multirow{2}{*}{$\mathbf{8 0} \%$} & $\mathbf{T} / \mathbf{C}$ & $1,813,831$ & $1,763,744$ \\
\cline { 2 - 4 } & $\mathbf{D} / \mathbf{C}$ & $2,234,828$ & $2,206,481$ \\
\hline \multirow{2}{*}{$\mathbf{7 0} \%$} & $\mathbf{T} / \mathbf{C}$ & $1,476,342$ & $1,431,619$ \\
\cline { 2 - 4 } & $\mathbf{D} / \mathbf{C}$ & $1,502,350$ & $1,460,355$ \\
\hline \multirow{2}{*}{$\mathbf{6 0} \%$} & $\mathbf{T} / \mathbf{C}$ & $1,149,327$ & $1,096,088$ \\
\cline { 2 - 4 } & $\mathbf{D} / \mathbf{C}$ & $1,159,132$ & $1,113,034$ \\
\hline
\end{tabular}

Table 3 shows the PSS/E simulation results of for each scenario. Each value is divided into the first and second half for the total power generation cost for one hour. The analysis of detailed cost changes by each period is as follows.

\subsubsection{First half of 2020/Second half of 2020}

In the first half of $2020 /$ second half of 2020 , it is confirmed that the total cost of all the load units is increased when the new generator of $1000 \mathrm{MW}$ is invested and the load of specific level is increased. Compared with the first half of the year for $100 \%$ load, the total power generation of the coal generators was increased by $1000 \mathrm{MW}$ and the combined generators was increased by $1180 \mathrm{MW}$ since newly introduced coal generator achieved additional power generation in second half of the year during the timely completion in order to cover the increased load(There is no change in power generation for nuclear power and other generators). The total cost shows the increase of about 200 million won. In the case of delayed completion, some new equipments are not operated, and so there is more increase of cost than timely completion since combined power generator should cover all the load increase. In the case of $80 \%$ load, the difference between the total cost of the timely completion and delayed completion is large. It's because that in case of the timely completion, the increased load can be covered only by the coal generator whereas in case of delayed completion, combined power generator should cover the increased load due to non-operation of low cost power generator. In the case of $70 \%$ and $60 \%$ load, the increase in total cost is smaller than that of other load because the increase in power generation belongs only to coal-fired generators in both timely completion and delayed completion.

\subsubsection{Second half of 2020/First half of 2021}


In the second half of 2020 and the first half of 2021, The1460MW will be put into operation as new equipment. We can confirm that the total power generation cost is reduced in all load units as nuclear power generator of the lowest cost was newly introduced. Actually in case of $100 \%$, the total power generation cost is reduced by 177 million won as the power generation of combined generator was decreased by $1460 \mathrm{MW}$ while the power generation by the nuclear power generator was increased by $1460 \mathrm{MW}$. In case of $80 \%$ load, there is a large difference in the change of total power generation cost between timely completion and delayed completion in the first half/second half of 2020. This is because there is larger change of cost as the power generation of the combined generator decreases in delayed completion whereas there is small change of cost as the power generation of coal generator decreases as much as the increased power generation of nuclear power generator. In case of $70 \%$ and $60 \%$ load, the change of total cost is small in both timely completion and delayed completion due to the decrease of power generation of coal generator.

\subsubsection{First half/Second half of 2021}

In the first half/second half of 2021, 2460MW of new generators will be introduced and the abolition of some generators will be reflected, and the load will increase by 2040MW and the total power generation cost increased at all loads. In case of $100 \%$ load, the nuclear power plant is newly introduced but the total power generation cost has increased due to the abolition of some generators and the increase by $870 \mathrm{MW}$ in combined facility capability due to load increase. In case of $80 \%$ load, the power generation of the combined generator increased in delay completion. However, in case of the completion of the timed completion, there is no change in the power generation of the combined generator and the power generation increased just in nuclear and coal generators, which results in significant increase in change of total cost.

\subsubsection{Second half of 2021/First half of 2022}

In the case of the second half of 2021/the first half of 2022 , there is no increase or decrease in the capacity of the entire power generation facilities, and also the load values are the same, which leads to the same result value.

\subsubsection{First half of 2022/Second half of 2022}

In the first half of 2022/the second half of 2022, there was no change in the total load and only $1460 \mathrm{MW}$ of new generators were introduced, which shows that the total generation cost is reduced in all load units. In case of $100 \%$ load, there was increase by $1460 \mathrm{MW}$ in nuclear power generation and decrease by $1460 \mathrm{MW}$ in combined power generation, which results in significant decrease in total power generation cost in timely completion. However, you can be see that the decrease in the total generation cost is small in the case of delayed completion, which means that for the delayed completion in the second half of 2022, one new nuclear power plant should be shut off and two coal generators should be shut off and therefore the power generation of nuclear power generators increases by $1460 \mathrm{MW}$ and the power generation of coal generators decreases by $1460 \mathrm{MW}$ when comparing with the second half of 2022. Total costs were reduced by about 30 million won in terms of cost. In case of $90 \%$ load, there is a difference in the total cost change between the timely completion and delayed completion due to the same reason as the $100 \%$ load, and the total load can be covered only by the nuclear power generator and the coal thermal power generator, which results in small change in total cost.

Table 4. Hours for each load level during one year

\begin{tabular}{|c|c|c|c|}
\hline Load & First half year & Second half year & Sum \\
\hline $\mathbf{1 0 0} \%$ & 132 & 63 & 195 \\
\hline $\mathbf{9 0} \%$ & 855 & 681 & 1536 \\
\hline $\mathbf{8 0} \%$ & 1768 & 1481 & 3249 \\
\hline $\mathbf{7 0} \%$ & 1229 & 1344 & 2573 \\
\hline $\mathbf{6 0} \%$ & 360 & 847 & 1207 \\
\hline Sum & 4344 & 4416 & $\mathbf{8 7 6 0}$ \\
\hline
\end{tabular}

Table 5. Accumulated generation costs for total three years. (Unit: billion KRW)

\begin{tabular}{|l|c|l|l|l|}
\hline & $\begin{array}{l}\text { Timely } \\
\text { completion }\end{array}$ & $\begin{array}{l}\mathbf{6} \text { month } \\
\text { delay }\end{array}$ & $\begin{array}{l}\mathbf{1 2} \text { month } \\
\text { delay }\end{array}$ & $\begin{array}{l}\mathbf{1 8} \text { month } \\
\text { delay }\end{array}$ \\
\hline Total cost & $47,600,512$ & $48,212,805$ & $49,012,567$ & $49,757,097$ \\
\hline Increased cost & 0 & 612,293 & $1,412,055$ & $2,156,585$ \\
\hline $\begin{array}{l}\text { Rate of } \\
\text { Increased cost }\end{array}$ & $0.00 \%$ & $1.29 \%$ & $2.97 \%$ & $4.53 \%$ \\
\hline $\begin{array}{l}\mathbf{2 4} \text { month } \\
\text { delay }\end{array}$ & $\begin{array}{l}\mathbf{3 0} \text { month } \\
\text { delay }\end{array}$ & $\begin{array}{l}\mathbf{3 6} \text { month } \\
\text { delay }\end{array}$ & \\
\hline Total cost & $50,918,317$ & $52,354,344$ & $53,669,436$ & \\
\hline Increased cost & $3,317,805$ & $4,753,832$ & $6,068,924$ & \\
\hline $\begin{array}{l}\text { Rate of } \\
\text { Increased cost }\end{array}$ & $6.97 \%$ & $9.99 \%$ & $12.75 \%$ & \\
\hline
\end{tabular}

Table 5 shows the calculation of accumulated generation costs for total three years by multiplying hourly generation cost for each scenario(which is shown in table 3) and hours for which each load level is applied during one year( 8,760 hours)(which is shown in table 4$)$. The values of table 4 is the average value of past three year load data of Korea. Timely completion indicates total cost for three years if transmission lines are completed until 2020, and after that time, total costs are presented for delays in the unit of six months. Cost differences compared with timely completion are represented as increased costs if line completion is delayed. If the construction of new transmission lines are delayed one year, about 1,410 billion won of cost increase is made. It can be found that about 3,300 billion won and about 6,000 billion won of costs have increased for two and three years of delay, respectively. 


\section{Conclusion}

This paper has proposed an OPF-based process for calculating constraint costs due to the construction of new transmission lines and used PSS/E OPF in order to perform case study for High Capacity transmission lines which will be constructed in Republic of Korea.

The OPF-based constraint cost calculation process which has been proposed by this paper may have theoretical limitations as it focuses on practical approach by replacing Unit Commitment with an algorithm to determine the operation status(On/Off) of units. It is judged, however, that this process can be a reasonable tool for future planning which considers uncertainty. It is also expected that accuracy can be improved by further study for linking with the Generator Maintenance Scheduling and Unit Commitment algorithms.

\section{References}

1. I.J Song, C.W Park, D.U Kang, M.J Bang, B.H Yun, Constrained Cost of the Transmission Line (1), KIEE.S.C, 154 (2006)

2. Y.C Kim, J.K Yoo, Blackout and Power System Operation, 515-516 (2015)

3. Dimitri P. Bertsekas, Constrained Optimization and Lagrange Multiplier Methods, MIT

4. SIEMENS, PSS/E $E^{T M} 30.2$ Users Manual, 2005

5. ROK MOTIE, $6^{\text {th }}$ Basic Plan for Long-Term Electricity Supply and Demand, 2013 